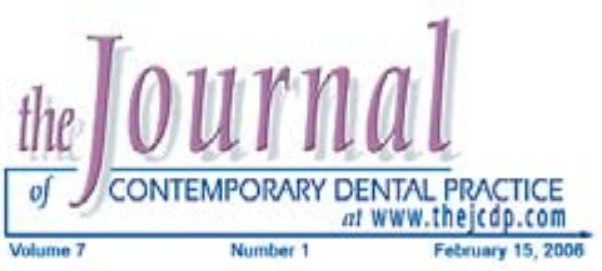

\title{
Report of Ankylosis of the Temporomandibular Joint: Treatment with a Temporalis Muscle Flap and Augmentation Genioplasty
}

\section{Wilson Denis Martins, DDS, PhD}

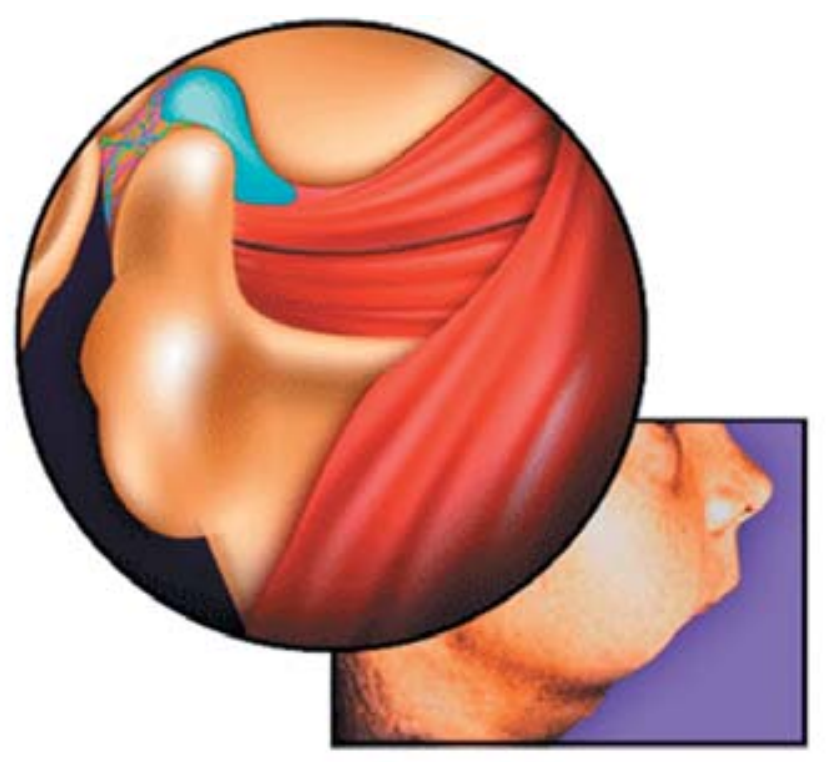

Abstract

A case of true bilateral ankylosis of the temporomandibular joint (TMJ) is presented. A 19-year-old male patient had a life-threatening ear infection at the age of ten resulting in a progressive restriction of his mouth opening. He presented with almost complete lack of mobility of the mandible. Surgical treatment was a resection of the ankylotic mass, interpositional temporalis composite muscle flaps, and early mobilization and aggressive physiotherapy. The functional results of the interpositional arthroplasty were excellent. After a twoyear follow up, an augmentation genioplasty was performed in order to improve facial aesthetics.

Keywords: Temporomandibular joint ankylosis, interpositional temporalis composite muscle flaps, interpositional arthroplasty

Citation: Martins WD. Report of Ankylosis of the Temporomandibular Joint: Treatment with a Temporalis Muscle Flap and Augmentation Genioplasty. J Contemp Dent Pract 2006 February;(7)1:125-133.

(C) Seer Publishing 


\section{Introduction}

Temporomandibular joint (TMJ) ankylosis is a structural disease that can cause asymmetry resulting in severe facial disfigurement as well as difficulties in eating, breathing, and speech. Should it occur before facial growth is completed, ankylosis produces micrognathia, especially if the disease is bilateral.

TMJ ankylosis was classified by Kazanjian ${ }^{12}$ as either true or false. True ankylosis is a condition that results in osseous of fibrous adhesion between the surfaces of the TMJ, within the limits of the articular capsule. False ankylosis results from diseases not directly related to the joint.

Various factors can cause TMJ ankylosis, including trauma, systemic and local infections, and neoplasms in the area. A higher incidence of post-traumatic ankylosis in children was reported by Laskin. ${ }^{14}$

Management of TMJ ankylosis is through surgical intervention as soon as the condition is recognized. Early surgery can minimize the severity of the restriction of facial growth.

The basic techniques for surgical correction of ankylosis include the gap arthroplasty ${ }^{16}$ (ressection of the bony mass without interpositional material); joint reconstruction (ressection of the bony mass with reconstruction by bone grafts or joint prosthesis); or interpositional arthroplasty (ressection of the bony mass with interposition of a biological material $^{18,21,22}$, or non-biological material). ${ }^{19,20}$

Costochondral grafts is the preferred biological material for TMJ reconstruction in children because it may allow additional mandibular growth. ${ }^{13,15}$ The interpositional arthroplasty with a temporal muscle flap is indicated by several authors. ${ }^{2,4,7,22}$

According to Laskin ${ }^{14}$, the principles of treatment of TMJ ankylosis are:

- operate as early as possible;

- keep the ramus high;

- prevent recurrence by using an interpositional material in growing patients, to replace the condylar growth center; and

- maintain a post-operative program of active jaw exercises.

\section{Case Report}

A 19-year-old young man was referred for treatment because of his long standing difficulty with opening his mouth. His medical history revealed a life-threatening right ear infection at the age of ten. After recovering from the ear infection, the patient experienced a slowly increasing restriction of his mouth opening. Extra-oral examination revealed a micrognathic mandible with the classic "bird's face" appearance of the patient. Some puctiform scars were visible in the right eye and pre-auricular regions (Figures 1 and 2).

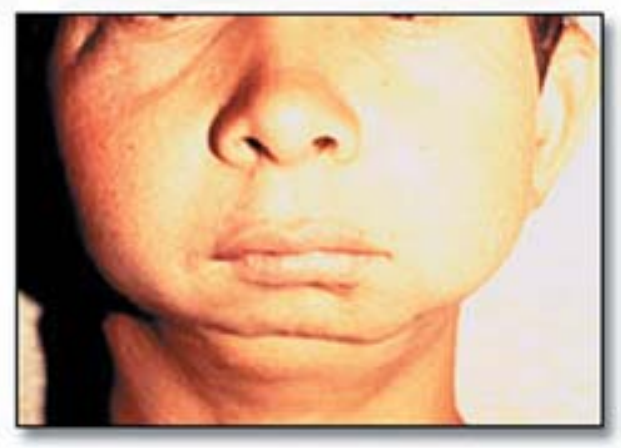

Figure 1.

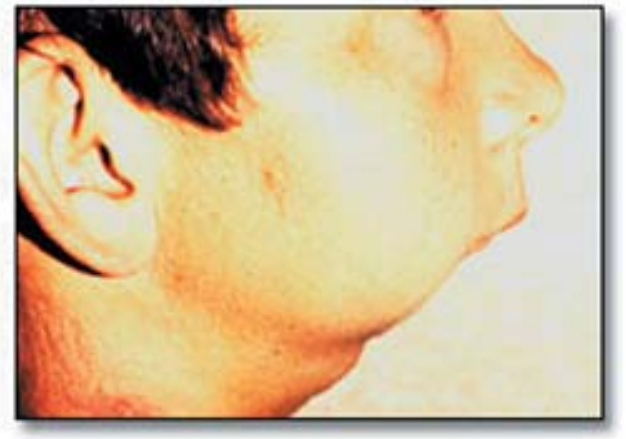

Figure 2.

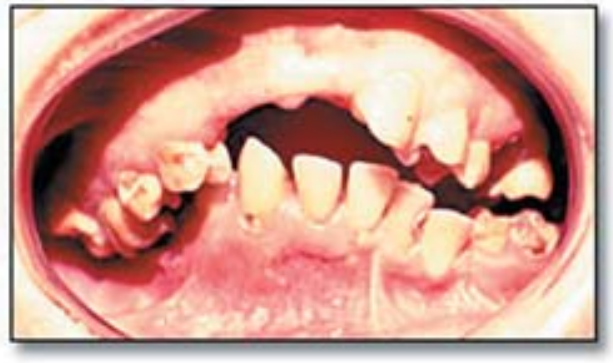

Figure 3. 


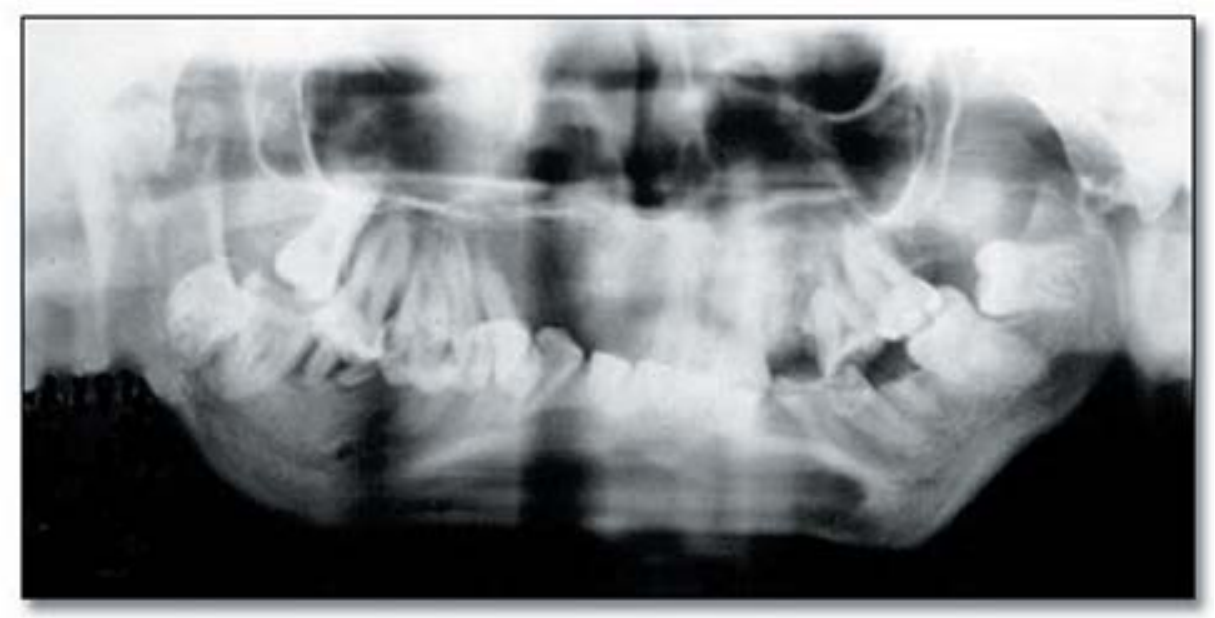

Figure 4.

Intra-oral examination revealed $0.5 \mathrm{~mm}$ of mouth opening, absence of the upper anterior teeth, and the presence of caries and periodontal disease (Figure 3).

Panoramic and transcranial radiographic examination revealed a lack of structural organization of both right and left joints.

Tomograms of the right side revealed a compact bony mass in place of the glenoid fossa and the condyle. On the left side, a less dense bony mass with a remaining condyle-like structure was found (Figures 4 to 8 ).

A diagnostic of bilateral TMJ ankylosis was made (true bony ankylosis in the right side and true fibrous ankylosis in the left side). Surgical treatment with interpositional temporal muscle flaps was selected. A tracheostomy had been previously performed.

\section{Treatment}

A surgical approach consisted of preauricular incisions as reported by Al-Kayat and Bramley. ${ }^{1}$ The zygomatic arch was exposed via an incision of the periosteum. On the left side, a condylelike structure and strong fibrous adhesions were found. The coronoid process was not identified. A gap was created by removing the fibrous/ osseus tissue with surgical burs and chisels. A "U-shaped" axial composite flap (fascia, muscle, and periosteum) was obtained from the exposed temporal muscle and rotated inferiorly under the zygomatic arch through the space created by the osteotomy. The flap was sutured medially, anteriorly, and posteriorly with 3-O Vicryl (Figures 9 to 11$)$.

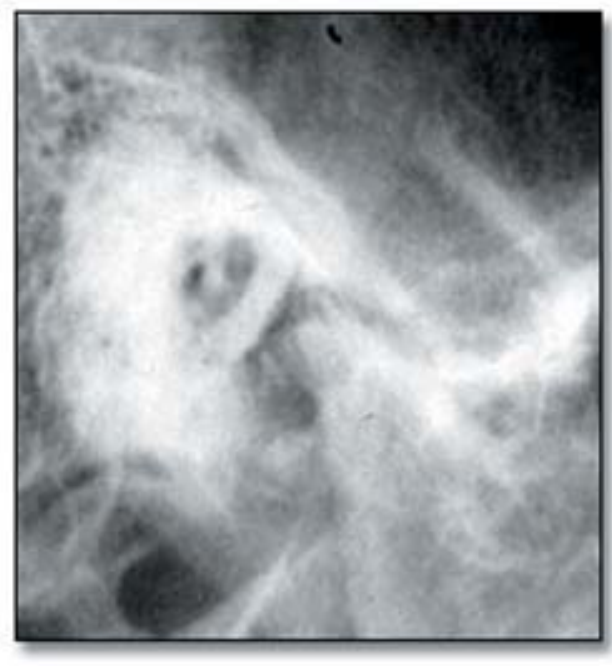

Figure 5.

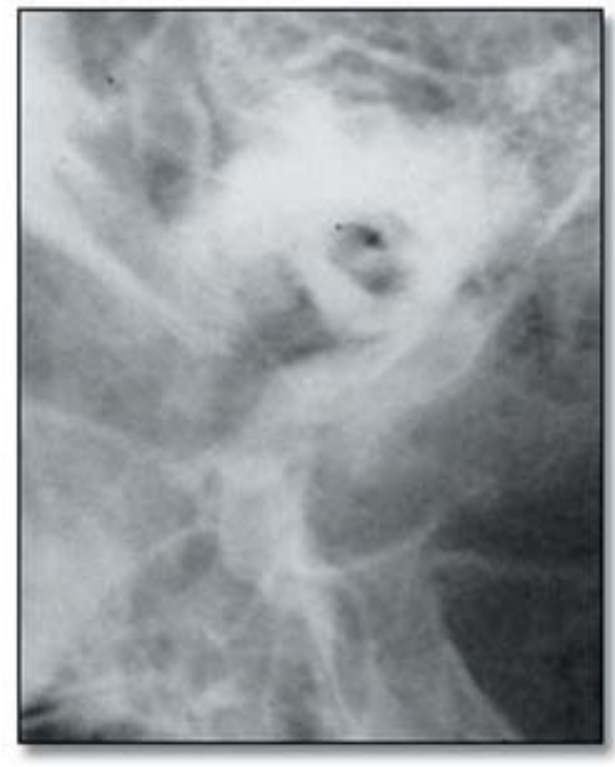

Figure 6. 


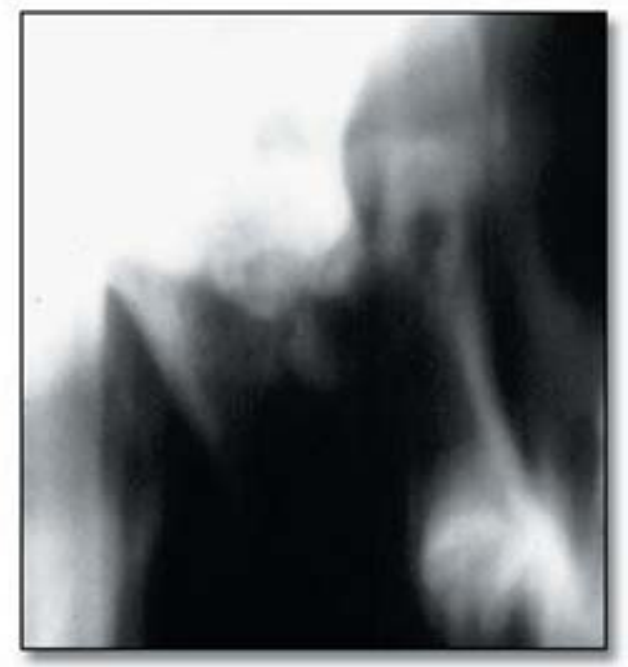

Figure 7.

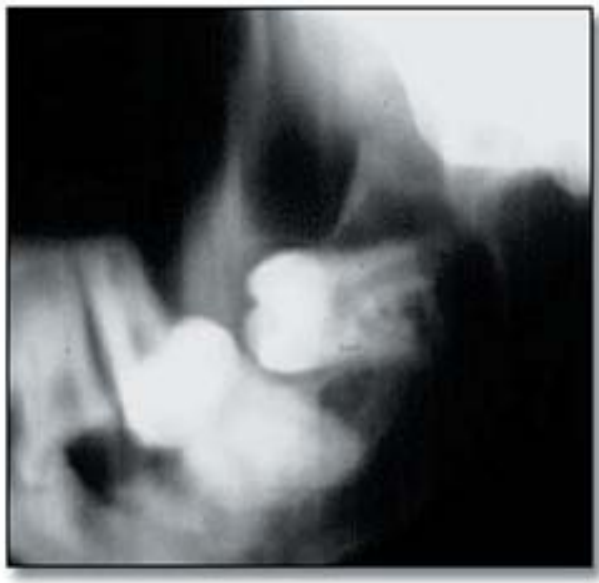

Figure 8.

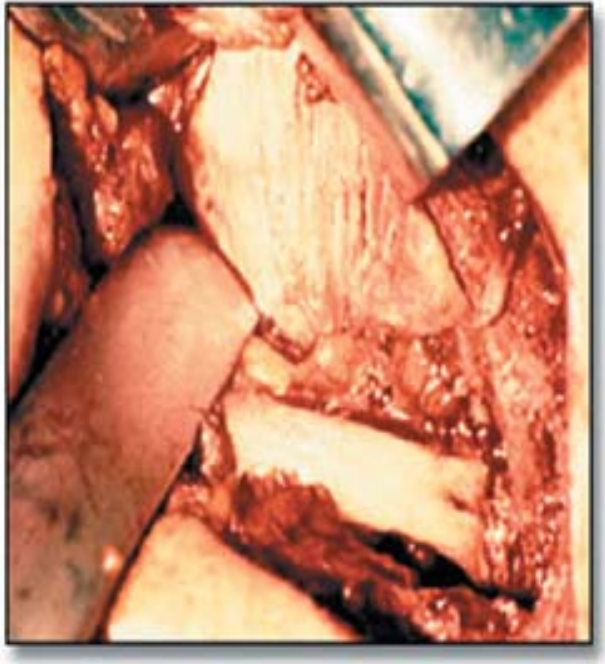

Figure 9.

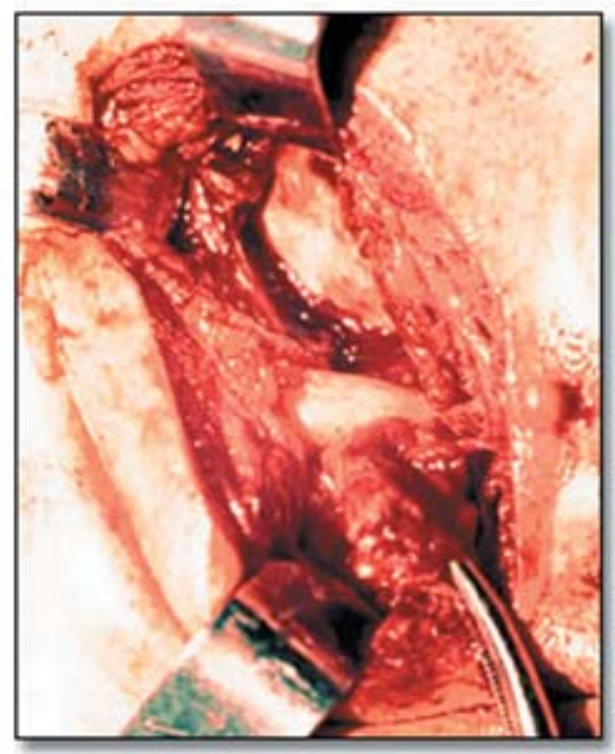

Figure 10.

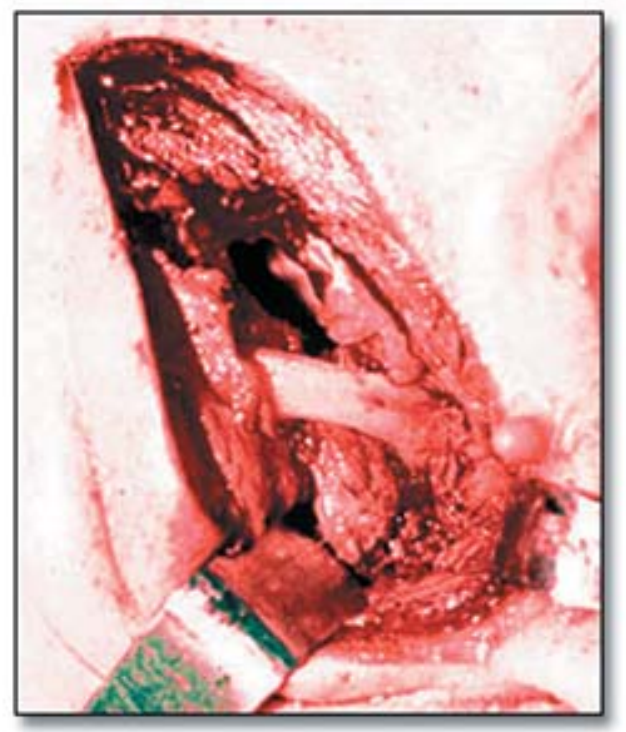

Figure 11.

In the right side a compact bony mass was found. Removal of the osseous mass required aggressive use of bone burs and chisels in order to create a surgical gap. A more extensive temporal flap was inferiorly rotated under the zygomatic arch (Figure 12). A maximum incisal opening of $50 \mathrm{~mm}$ was obtained after the osteotomies (Figure 13).

\section{Post-operative Course}

The post-operative (PO) course was uneventful. Only PO pain medication was prescribed. There was no motor deficit on either side of the face. Vigorous PO physiotherapy was performed to 


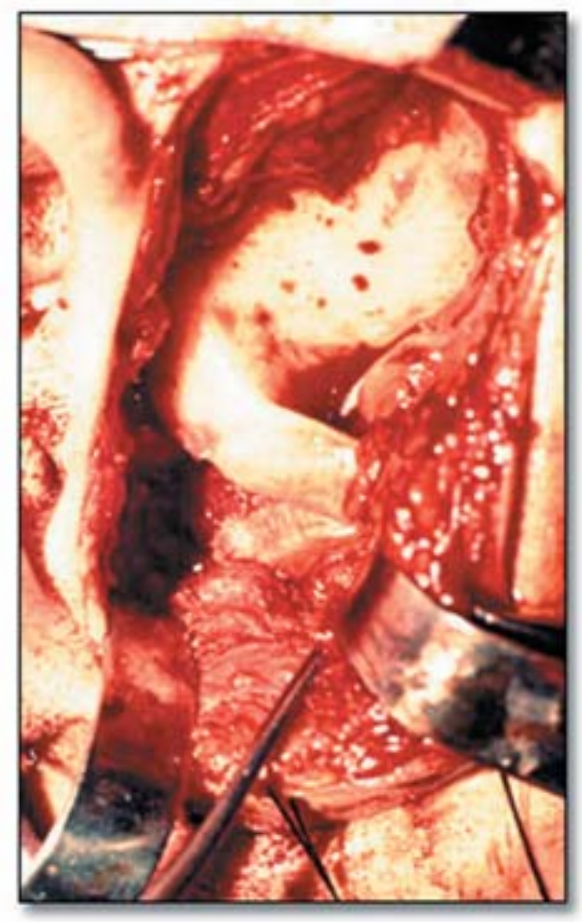

Figure 12.

maintain the mobility and to prevent hypomobility secondary to fibrous adhesions. The patient was followed at six months, one, and two-year intervals, with a maximum mouth opening of 50 $\mathrm{mm}$ (Figures 14 and 15). A panoramic radiograph (two years PO) showed no signs of recurrence (Figure 16).

\section{Genioplasty}

After two years, an augmentation genioplasty was performed in order to improve the facial balance of the patient. A $10 \times 40 \mathrm{~mm}$ block of sculpted solid silicone rubber was adapted and fixed with $1.0 \mathrm{~mm}$ wires by intra-oral access (Figure 17).

The final aspect of the patient is shown in Figure 18.

\section{Discussion}

The principal advantages of the temporalis muscle and fascia flap are their autogenous nature, resilience, and adequate blood supply. Its proximity to the joint allows for a pedicled transfer of vascularized tissue into the joint area. $^{22}$ In this case a composite (fascia, muscle, and periosteum) axial flap was harvested, as described by Herbosa and Rotskoff. ${ }^{9}$

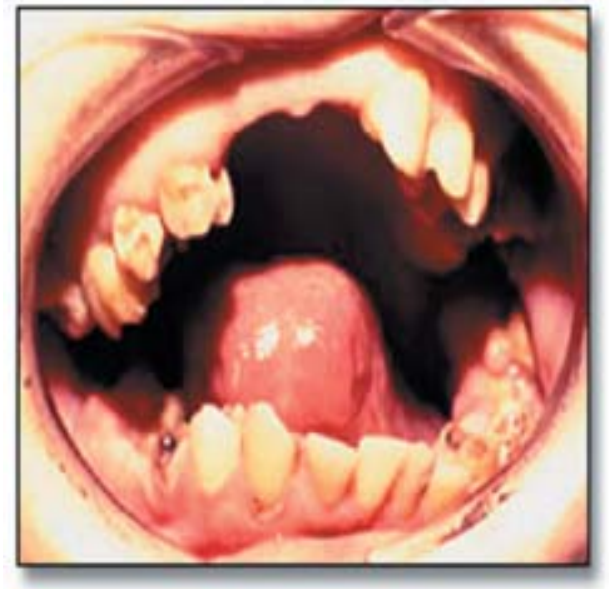

Figure 13.

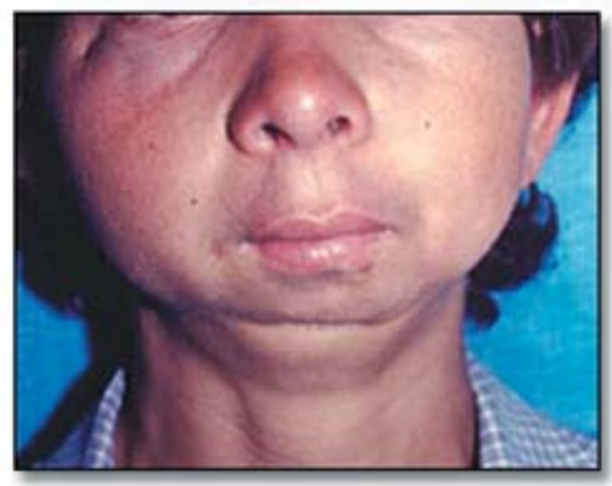

Figure 14.

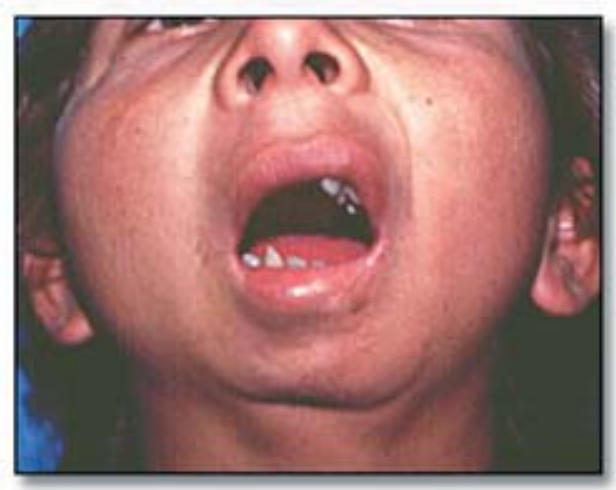

Figure 15.

The axial flaps were easily rotated inferiorly under the zygomatic arch and into the joint space. Rotation under the zygomatic arch prevents bulkiness and avoids the need for surgically reducing the thickness of the zygomatic arch, as suggested by Pogrel and Kaban ${ }^{18}$, when rotating the muscle over the arch. 


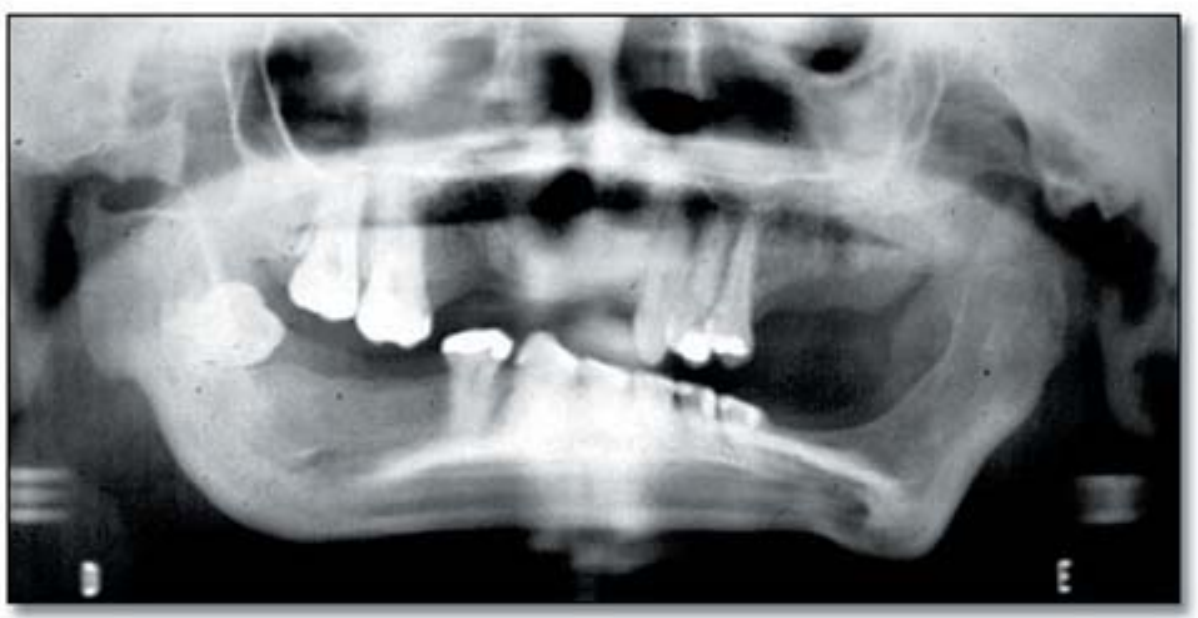

Figure 16.

Summary

Regarding the fate of the temporalis muscle graft, Umeda et al. ${ }^{23}$ have demonstrated by magnetic resonance imaging the flaps appeared to be viable and the tissue signal was compatible with vital muscle and/or fat as opposed to tissue scarring.

For the two year follow-up observation of this case, the success may be considered excellent based on the increased mobility of the mandible and improvement of function

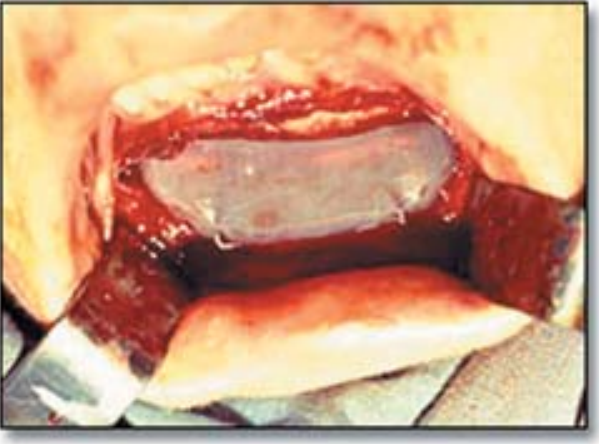
and facial aesthetics.

Figure 17.

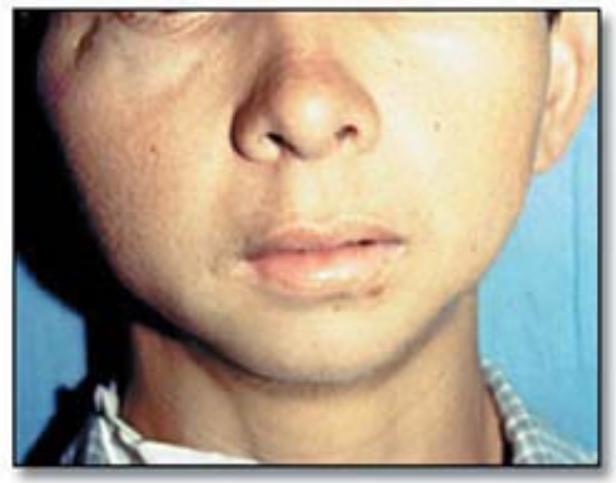

Figure 18. 


\section{References}

1. Al Kayat A, Bramley P. A modified pre-auricular approach to the temporomandibular joint and malar arch. Br J Oral Surg 1979;17:91-103.

2. Brusati $R$, Raffaini $M$, Sesenna $E$, et al. The temporalis muscle flap in temporo-mandibular joint surgery. J Craniomaxillofac Surg 1990;18: 352-358.

3. Chidzonga MM. Temporomandibular joint ankylosis: review of thirty-two cases. Br J Oral Maxillofac Surg 1999;14:136-138.

4. Clauder L, Curioni C, Spanio S. The use of the temporalis muscle flap in facial and craniofacial reconstructive surgery. A review of 182 cases. J Craniomaxillofac Surg 1995;23: 203-14.

5. El-Sheikh MM, Medra AM. Management of unilateral temporomandibular ankylosis associated with facial asymmetry. J Craniomandibular Surg 1997;25:109-115.

6. Faerber E, Ennis LR, Allen GA. Temporomandibular joint ankylosis following mastoiditis:report of case. J Oral Maxillofac Surg 1990; 48: 866-870.

7. Feinberg SE, Larsen PE. The use of a pedicled temporalis muscle-pericranial flap for replacement of the TMJ disc: preliminary report. J Oral Maxillofac Surg 1989;47:142-146.

8. Guthua SW, Maina DM, Kahugu M. Management of post-traumatic temporomandibular joint ankylosis in children: case report East Afr Med J 1995;72:471-475.

9. Herbosa EG, Rotskoff KS. Composite temporalis pedicle flap as an interpositional graft in temporomandibular joint arthroplasty: a preliminary report. J Oral Maxillofac Surg 1990;48:1049-56.

10. Kaban LB, Perrot D, Fisher K. A protocol for management of temporomandibular joint ankylosis. J Oral Maxillofac Surg 1990; 48:1145-1151.

11. Karaca C, Barutcu A, Menderes A. Inverted T-shaped silicone implant for the treatment of TMJ ankylosis. J Craniofac Surg 1998; 9:539-42.

12. Kazanjian VH. Temporomandibular ankylosis. Am J Surg 1955; 90: 905.

13. Ko EW, Huang CS, Chen YR. Temporomandibular reconstruction in children using autogenous costochondral grafts. J Oral Maxillofac Surg 1999; 57:789-798.

14. Laskin DM. Role of the meniscus in the etiology of postraumatic temporomandibular joint ankylosis. Int J Oral Surg 1978;7:340-345.

15. Lindqvist $\mathrm{C}$, Pihakari A, Tasanen A, et al. Autogenous costochondral grafts in TMJ arthroplasty. A survey of 66 arthroplasties in 60 patients. J Maxillofac Surg1986;14:143-149.

16. Manganello-Souza LC, Mariani PB. Temporomandibular joint ankylosis: report of 14 cases. Int $J$ Oral Maxillofac Surg 2002;32:24-29.

17. Mclntosh RB. The use of autogenous tissues for temporomandibular joint reconstruction. J Oral Maxillofacial Surg 2000;58:63-69.

18. Pogrel MA, Kaban LB. The role of a temporalis fascia and muscle flap in temporomandibular joint surgery. J Oral Maxillofac Surg 1990;48:14-19.

19. Salins PC. New perspectives in the management of craniomandibular ankylosis. Int J Oral Maxillofac Surg 2000;29:337-340.

20. Sanwhney CP. Bony ankylosis of the temporomandibular joint: follow up of 70 patients treated with arthroplasty and acrilyc spacer interposition. Plast Reconstruc Surg 1986;77:29-38.

21. Smith JA, Sandler NA, Ozaki WH, et al. Subjetive and objective assessment of the temporal myofascial flap in previously operated temporomandibular joints. J Oral Maxillofac Surg 1999; 57 : 1058-1065.

22. Su-Gwan K. Treatment of temporomandibular joint ankylosis with temporalis muscle and fascia flap. Int J Oral Maxillofac Surg 2001;30:189-93.

23. Umeda H, Kaban LB, Pogrel MA, et al. Long-term viability of temporalis muscle/fascia flap used for temporomandibular reconstruction. J Oral Maxillofaci Surg 1993;5:530-535. 
About the Author

\section{Wilson Denis Martins, DDS, PhD}

Dr. Martins is an Oral and Maxillofacial Surgeon and a Professor of Stomatology at the Catholic University of Parana (PUCPR) in Curitiba, Brazll.

e-mail:w.denis@pucpr.br 